\title{
SPATIAL AND TEMPORAL ELECTRIC VEHICLE DEMAND FORECASTING IN CENTRAL LONDON
}

\author{
Salvador ACHA \\ Imperial College London, UK \\ salvador.acha@imperial.ac.uk
}

\author{
Koen H. VAN DAM \\ Imperial College London, UK \\ k.van-dam@imperial.ac.uk
}

\author{
Nilay SHAH \\ Imperial College London, UK \\ n.shah@imperial.ac.uk
}

\begin{abstract}
If electricity infrastructures are to make the most of electric vehicle (EV) technology it is paramount to understand how mobility can enhance the management of assets and the delivery of energy. This research builds on a proof of concept model that focuses on simulating EV movements in urban environments which serve to forecast EV loads in the networks. Having performed this analysis for a test urban environment, this paper details a case study for London using an activity-based model to make predictions of EV movements which can be validated against measured transport data. Results illustrate how optimal EV charging can impact the load profiles of two areas in central London - St. John's Wood \& Marylebone/Mayfair. Transport data highlights the load flexibility a fleet of EVs can have on a daily basis in one of the most stressed networks in the world, while an optimal power flow manages the best times of the day to charge the EVs. This study presents valuable information that can help in begin addressing pressing infrastructure issues such as charging point planning and network control reinforcement.
\end{abstract}

\section{INTRODUCTION}

In order for electrical infrastructure to properly adapt and make the most of the deployment of electric vehicles (EVs), it is imperative that energy stakeholders address the challenges these units bring to utilities, from the additional stochastic load to their inherited mobility as they seemingly randomly appear and disappear from the network. Furthermore, as EVs become an increasing transport medium in urban areas, distribution network operators (DNOs) and other parties will be pressed to develop and use reliable forecasting models to estimate the daily energy requirements these vehicles will represent for different areas of a city; most likely each day of the week and each part of the network will have distinctive consumption behaviours [1]. To achieve this goal, it is elemental to accurately portray vehicle usage patterns. Once the detailed temporal and spatial energy demands of EVs are estimated it is possible to assess various charging scenarios with the overreaching goal of identifying what charging strategies are the most cost-effective to stakeholders [2].

EV load forecasting is mostly an unknown topic for power engineers since these are not very familiar with transport system studies. This gap needs to be filled if successful EV integration with the grid is to occur. This implies that researching the way how these vehicles are used and its interaction with the road infrastructure is essential to optimise how, where, and when the vehicles may be recharged. This paper employs and enhances agent-based modelling principles while also using survey data as a reference to estimate, with a great level of granularity, the energy use of EVs in a part of central London. Thus, to make cities smarter, integration of sub-systems such as transport and electricity infrastructures has to be sought; consequently insights can help provide new services to make cities more efficient in the manner they use energy.

\section{MODELLING MOBILITY CHARACTERISTICS OF ELECTRIC VEHICLES}

Mobility of vehicles can be modelled in macro- or microsimulation models. The former approach considers flows of traffic expressed in numbers of vehicles on a road network using origin and destination distributions. This is a useful and trusted approach (e.g. VISUM) for describing large networks, but has significant shortcomings in that it cannot easily represent dynamic effects such as bottlenecks. Microsimulation, on the other hand, models the individual behaviour of drivers and their choices (e.g. TRANSIM or VISSIM). In other words, they not only simulate the mean values but can provide disaggregate output.

Micro-simulation approaches, often using the agent-based paradigm, have recently been used in EV studies to study the impact on the electricity grid by modelling vehicle usage patterns and evaluating charging strategies (e.g. [3, 4, 5, 6 and 7]). However, this work typically addresses the network at the transmission level rather than more detailed distribution level. Peak-shaving/valley filling strategies can thus be studied to determine when the vehicles should be charged, but there is less emphasis on where this takes place. This fine-grained spatial component is relevant when considering capacity restrictions of the substations, but also for planning the charging infrastructure as well as influencing behaviour of individual vehicle users.

In previous work $[1,2]$ an agent-based model developed in the Repast Simphony toolkit to generate trips in a (made-up) urban environment has been used. A GIS shapefile was read containing the location of different types of buildings including homes, offices, shops and schools, as well as a road network connecting the neighbourhoods of the city. Its corresponding medium voltage $11 \mathrm{kV}$ distribution network was also described in a similar way, marking the location of the substations. Furthermore, a limited number of driver profiles was created which prescribed daily routines (e.g. driving to school, then continue to work, etc) from which random distributions were drawn to create variation in the trips between people with the same profile and over different days of the week (e.g. people would be more likely to return home late at night on a Friday than on a Thursday). 
The advantage of this approach is the ability to develop multiple case studies by adjusting driver profiles and vehicle characteristics or even the layout of the city. Most important, however, is the capability to keep track of the individual battery status of each vehicle and its location. Having full control over the way the model is set up means there is flexibility in designing the interface with a power flow model in which adding the EV load terms is quite straight-forward. Nonetheless, validating driver behaviour with real data sets, for example from transport surveys or measured trip data, is difficult and creating new driver profiles to represent additional categories of users can be cumbersome. As a note, the effects of congestion on driving speeds or route choice could not be taken into account in the basic routing model used.

As said, transport engineers already research and use (micro-) simulation models describing predicted traffic flows on a road network given a certain city layout, landuse, and population characteristics. In this paper we describe an attempt to re-purpose the output of such a model which has been validated with transport surveys and represents realistic movement of people. This leads to more realistic forecasts of EV loads over space and time and provides the opportunity to link the data with the layout of a real distribution grid as well as the "static" electricity loads for the same urban area.

\section{MODELLING THE IMPACT OF ELECTRIC VEHICLES ON THE ELECTRICITY GRID}

To guarantee EV load flexibility is properly exploited by stakeholders, various charging strategies need to be assessed on a like for like basis to better comprehend their respective trade-offs. Smart charging is a relevant topic in the literature but it is usually modelled at a high voltage level [8], rarely detailing the phenomena relevant to low voltage (LV) networks - the first point of contact between EVs and the power infrastructure. Independent of the charging rate, strategies considered thus far in the literature can be classified into two major groups with their own subcategories; these are [9]:

- Uncoordinated charging: Implies no advanced algorithms trigger the charging on/off periods of EVs (i.e. plug and forget scenarios). Consequently, charging occurs whenever vehicles are plugged-in or alternatively using a start delay timer when a more attractive tariff is offered (e.g. Economy-7).

- Coordinated charging: Refers to predefined multicriteria algorithms that replicate smart charging strategies of EVs embedded in LV networks. These actions usually aim at reducing energy costs, network losses, and/or transport emissions.

Findings from evaluating various charging strategies of EVs in LV networks state that in areas with high penetration and no charging coordination will likely require voltage control mechanisms and an upgrade of cable capacity [10]. Ideal LV network smart-charging strategy solutions will be casespecific, but nevertheless generic studies show that EVs furthest away to substations will create the most losses; thus it is particularly here where DNOs need to enhance their monitoring and control capabilities [11]. Likewise, a coordinated charging approach reduces power losses and improves the load factor of the network - this can be done by aiming to reduce thermal loading of the cables [10] and/or by obeying flexible tariffs that closely reflect the spot prices of energy [12]. Nevertheless, it is important to note that smart charging is not without costs [13].

\section{METHODOLOGY}

This research builds on a proof of concept model that focused on simulating EV movements and the optimal delivery of energy for their charging. Based on the idea of a model sharing platform $[14,15]$, in which models of various infrastructure sub-systems are connected in a chain and the output of one model serves as an input to another, a three step approach is taken. Firstly, we employ a transport model which generates trips across the city based on the activities of "agents" which take place in a specific area and at a certain time $[16,17]$. For example, agents travel from their home to the office in the morning and back in the evening, perhaps stopping in a leisure centre or shop, etc.

The output of the first model, namely trips made by the synthetic population, is processed by a second model which translates these journeys into temporal and spatial electricity demands (assuming journeys are made by EVs). This model takes vehicles characteristics into account and matches the location of the EVs with the nearest substation. For each time period considered, the actual and maximum state of charge (SOC) is logged. The gap between the two values is the load flexibility of charging vehicles over time and space. This flexibility then is used as input to a third model, which is a time coordinated optimal power flow (TCOPF) program [9]. The TCOPF simulation takes the role of an intermediary that assigns the most convenient times EV load can be satisfied according to grid conditions and other factors such as electricity prices; effectively coordinating a subtle integration of EVs with the power networks.

Having performed the multi-faceted analysis detailed above for a virtual city $[1,2]$, assessing an area of a real city using real network layouts (both road and electricity networks) combined with simulated data of a synthetic population was deemed as the next step in this research.

\section{CASE STUDY: DEMAND FORECASTING IN LONDON, UK}

To showcase the scope and methodology required to perform an in-depth analysis of EV travelling profiles in real transport networks, a case study has been executed for a part of London, UK. Two distinct neighbourhoods, both in central London, are considered. One is the predominantly residential St John's Wood and the other is characterised by a high density of retail and office buildings mixed with some housing around Oxford Street; including the Mayfair and Marylebone areas.

To build the model various (open) data sets have been used to determine electricity loads and EV mobility such as 
population characteristics, infrastructure layout, and land use. Table 1 shows some of the key data used. The data sets were obtained from the Office of National Statistics [18] at the Middle Super Output Level (Zone Westminster011 and Westminser002 respectively); making it possible to derive static electricity loads for the two zones and estimate electric vehicle ownership. Vehicle journeys originating from either of these areas as well as trips into these neighbourhoods were generated using the above mentioned simulation model. For the electricity grid the two $11 \mathrm{kV}$ substations linked to the $132 \mathrm{kV}$ line entering London at $\mathrm{St}$ John's Wood were modelled. These substations are in Duke Street W1, which covers the shops and offices around Oxford Street, and Aberdeen Place NW8, which supplies the mostly residential St John's Wood - see Figure 1.

During the night, EVs in the St. John's Wood area have a big presence, assumed to be around $65 \%$ penetration, while in the Marylebone/Mayfair area this is about $20 \%$. However, these values drastically change during the day as vehicles in St. John's Wood are reduced and many arrive to the Marylebone/Mayfair area to do work and leisure activities. As part of the charging optimisation algorithm it is specified that all EVs need to be fully charged by 4 a.m. under the premise to charge when electricity spot prices are lowest and the voltage levels in the network can cope with extra power delivery; making sure EVs are ready for use in the morning. It was assumed plug-in points are available everywhere in central London at a fixed rate of $3.6 \mathrm{~kW}$.

Table 1 - Key input data used for the London case study [18]

\begin{tabular}{|c|c|c|}
\hline Metric & St. John's Wood & Marylebone/Mayfair \\
\hline Number of cars & 2,455 & 2,413 \\
\hline Domestic space & $73 \%$ & $33 \%$ \\
\hline Retail space & $20 \%$ & $24 \%$ \\
\hline Office space & $7 \%$ & $43 \%$ \\
\hline
\end{tabular}

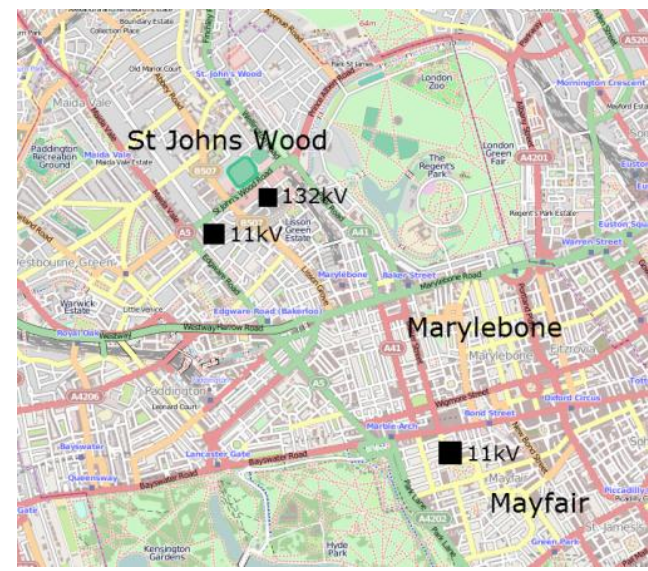

Figure 1 - Map of the study area in Central London. (C) OpenStreetMap contributors

\section{RESULTS}

\section{Spatial and temporal EV representation}

Figure 2 shows the number of vehicles plugged-in for the two neighbourhoods by giving the aggregated state-ofcharge (SOC) of the EV batteries. St. John's Wood, being a residential area, has people using their car during the day and the highest number of vehicles parked during the night. In a neighbourhood with offices and shops, such as Marylebone/Mayfair, people visit during the day which makes the number of vehicles plugged-in higher in the afternoon and lower during the night. Figure 3 displays the gap between maximum and current aggregated SOC of the EV batteries in the two neighbourhoods as generated by the activities of the agents; thus giving the EV load flexibility available to the network. Determining EV load flexibility or charging capacity at different times of the day is a key piece of information required to properly devise EV demand response services in smart-grid schemes. Naturally, this load flexibility will be highly dependent on travel requirements of EV owners and the areas where EVs are concentrated.

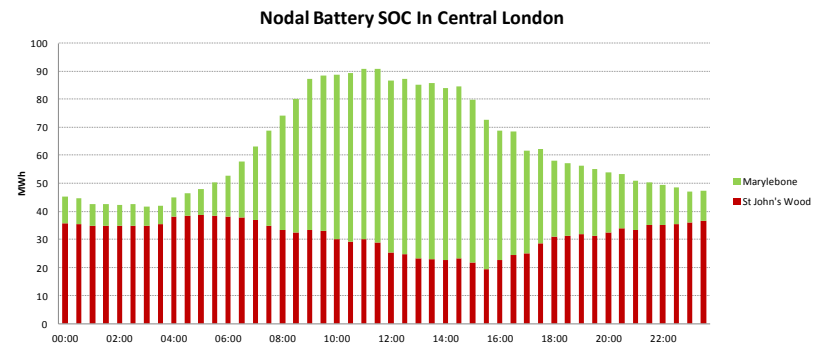

Figure 2-EVs arrive in commercial areas during the day, while in residential areas drivers are out with their car.

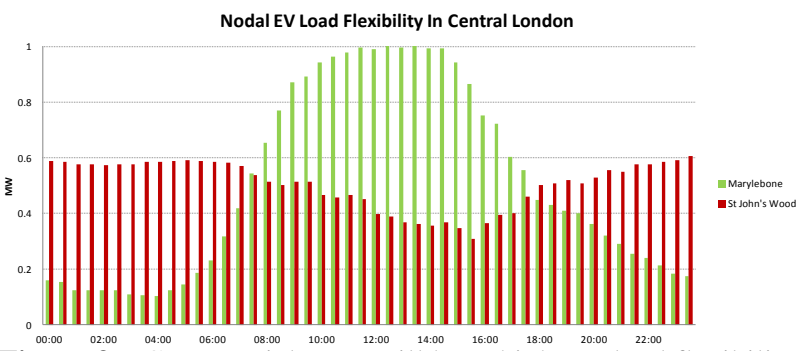

Figure 3-Commercial areas will have high EV load flexibility during the day while residential areas will have it at night time.

\section{Optimised load profiles and EV charging.}

Figures 4 and 5 depict the daily load profile of each area being analysed. The energy density is higher in the Marylebone and Mayfair areas and thus the capacity needed to satisfy is much larger. As expected St. John's Wood has a more domestic profile and EVs charge mostly during the late night and early morning hours. Meanwhile, in the Marylebone/Mayfair area EV charging occurring during the day goes mostly unnoticed as office and retail load is so overwhelming, despite the fact that there are more EVs in this area than in St. John's Wood. Figure 6 gives an indepth look at how optimal EV charging would take place in each area of London making the most of the load flexibility available. In St. John's Wood charging focuses at night time, while in Marylebone/Mayfair charging is sporadic throughout the day. Results showcase that adequate EV charging schemes should not represent major issues to DNOs if voltage control mechanisms are in place and holistic smart charging aggregation services are available. 


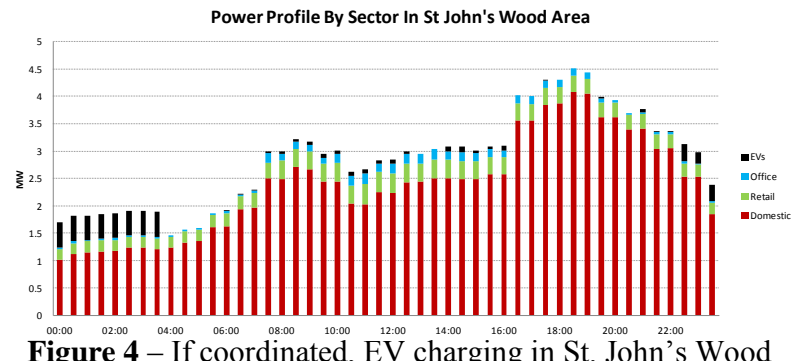

Figure 4 - If coordinated, EV charging in St. John's Wood should go unnoticed by customers and utility stakeholders.

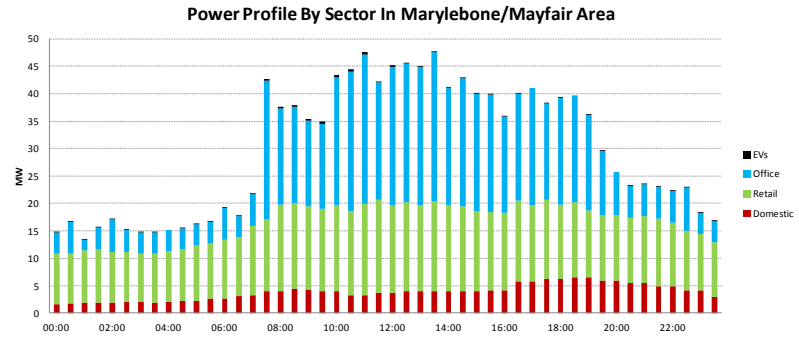

Figure 5 - High power demand in central London makes it easy for EV charging to go unnoticed.

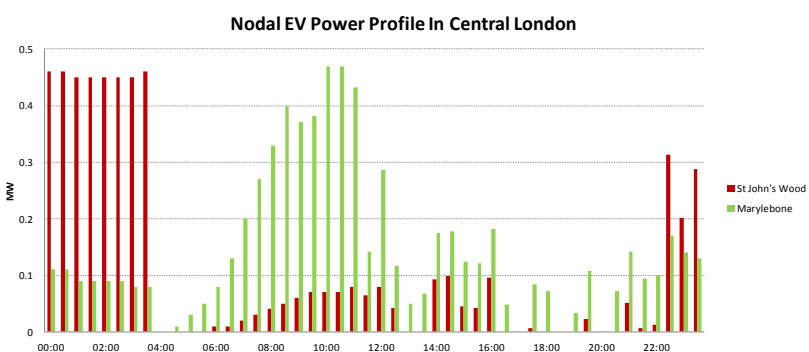

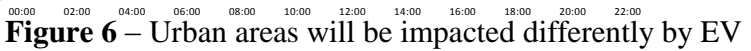
charging, it seems most charging will occur in residential areas.

\section{CONCLUSIONS AND FUTURE RESEARCH}

Addressing the temporal and spatial impacts of EV charging in electrical networks is a necessary step towards achieving a robust and effective smart-grid. This paper has employed agent-based principles while also using census data as a reference to calculate the optimal energy use of EVs in a part of central London; making clear integrating transport and power system models appropriately addresses the holistic requirements of such a complex problem. Results from this work highlight estimated energy demand a fleet of EVs can have on a daily basis in one of the most stressed networks in the world, thus providing valuable information to begin addressing pressing infrastructure issues such as charging infrastructure planning, network control and reinforcement, and estimated levels of additional energy that will need to be delivered by DNOs to satisfy EV users. Further work is required in both transport and power flow models. The transport model could be enhanced by detailing greater level of journey requirements based on specific user types. Likewise, the power flow model could be improved by considering making more realistic assumptions on charging points and the impacts of fast/slow charging in three-phase networks. Finally, research is also needed in EV tariff frameworks that properly portray the trade-offs stakeholders will face based on temporal and spatial issues - a key component in the journey towards smart charging.

\section{Acknowledgments}

This research was done within the Digital City Exchange project funded by the Research Council (EPSRC Grant No. EP/I038837/1). The authors also thank Dr A. Sivakumar and Prof J. Polak for sharing their transport model.

\section{REFERENCES}

[1] Acha, S., van Dam, K.H., Keirstead, J. and Shah, N., "Integrated modelling of agent-based electric vehicles into optimal power flow studies," Proceedings of CIRED 2011. pp.1-4, 6-8 June 2011.

[2] Acha, S., van Dam, K.H., Shah, N. "Modelling Spatial and Temporal Agent Travel Patterns for Optimal Charging of Electric Vehicles in Low Carbon Networks," IEEE Power and Energy Society General Meeting, pp.1-8, San Diego, CA, USA. 22nd -26th July 2012.

[3] Kang, J. E. and Recker, W.W. An activity-based assessment of the potential impacts of plug-in hybrid electric vehicles on energy and emissions using 1-day travel data, Transp. Research Part D: Transport and Environment, 14(8): 541-556, 8, December 2009

[4] Galus, M.D., "Agent-based modeling and simulation of large scale electric mobility in power systems", PhD Thesis, ETH Zurich, 2012.

[5] Waraich, R.A., Galus, M.D., Dobler, C., Balmer, M., Andersson,G., Axhausen, K.W., Plug-In Hybrid Electric Vehicles and Smart Grids: Investigations based on a Microsimulation. Submitted to Transportation Research Part C, 2012

[6] Knapen, L. Kochan, B., Bellemans, T, Janssens, D. and Wets, G. Using activity-based modeling to predict spatial and temporal electrical vehicle power demand in Flanders, The Transportation Research Board (TRB) 91st Annual Meeting, 2012

[7] Stephens, T. "An Agent-Based Model of Energy Demand and Emissions from Plug-in Hybrid Electric Vehicle Use", MSc thesis, University of Michigan, 2010

[8] National Renewable Energy Laboratory (NREL). (2007, May.). "Costs and Emissions Associated with Plug-in Hybrid Electric Vehicle Charging in the Xcel Energy Colorado Service Territory", [Online]. Available: www.nrel.gov/docs/fy07osti/41410.pdf [Accessed: 14 January 2013].

[9] Acha, S. Modelling Distributed Energy Resources in Energy Service Network, IET Press, London, 2013 (in press).

[10] Richardson, P.; Flynn, D.; Keane, A. "Optimal Charging of Electric Vehicles in Low-Voltage Distribution Systems,", IEEE Transactions on Power Systems, vol.27, no.1, pp.268-279, Feb. 2012.

[11] Acha, S.; Green, T.; Shah, N., "Effects of Optimised Plug-in Hybrid Vehicle Charging Strategies on Electric Distribution Network Losses", Transmission and Distribution Conference and Exposition, 2010 IEEE PES , pp.1-6, 19-22 April 2010.

[12] Acha, S.; Green, T.C.; Shah, N., "Optimal charging strategies of electric vehicles in the UK power market," Innovative Smart Grid Technologies (ISGT), 2011 IEEE PES, pp.1-8, 17-19 Jan. 2011.

[13] Clement-Nyns, K.; Haesen, E.; Driesen, J.; , "The Impact of Charging Plug-In Hybrid Electric Vehicles on a Residential Distribution Grid," IEEE Trans on Power Systems, , vol.25, no.1, pp.371-380, Feb. 2010

[14] van Dam, K.H., Acha, S., Sivakumar, A., Polak, J.W. and Shah, N. Smart cities through data, models and services - a model exchange platform. In Digital Futures 2012, Aberdeen, UK, 23-25 October 2012

[15] van Dam, K.H., Tsinalis, O., Sivakumar, A., Shah, N., Guo, Y. and Polak, J.W. Introducing a model composition platform for urban energy and transport systems. In Proc. of the Third International Workshop on Agent Technologies for Energy Systems (ATES 2012) at AAMAS2012, pages 103--104, Valencia, Spain, 5 June 2012

[16] Keirstead, J. and Sivakumar, A.. Using activity-based modelling to simulate urban resource demands at high spatial and temporal resolutions. Journal of Industrial Ecology 16(6): 889-900, Dec 2012

[17] Sivakumar, A., Vine, S. L. and Polak, J.W. An activity-based travel demand model for London. In Proceedings of the European Transport Conference, Glasgow, UK, October 2010.

[18] Office for National Statistics. Neighbourhood statistics and census results. http://www.neighbourhood.statistics.gov.uk/, 2012. 